\title{
Measurements of evaporation from fallow Sahelian savannah at the start of the dry season
}

\author{
By J. H. C. GASH. J. S. WALLACE. C. R. LlOYD. A. J. DOLMAN. \\ Institute of Hydrology, Wallingford
}

M. V. K. SIVAKUMAR and (. RENARD)

International Crops Research Institute for the Semi-Arid Troptcs (ICRISAT). Sahelan ('enter. BP 124(14. Niame'y, Niger

(Recenced 2n June 1401), rewed 12 rehruan $(x) 1)$

\section{SIMMARY}

Micrometeorological measurements of evaporation were made for the first six weeks of the dry season at a fallow savannah site in the Sahel. The evaporation fell from typically $4.5 \mathrm{~mm}$ per day at the start of the dry season to $1.5 \mathrm{~mm}$ per day six weeks later. The surface conductance was modelled in terms of emperical functions of time of day, and the number of days since the final rain of the season. It was found that there was little variation in surface conductance within cach day, with no significant correlation with solar radiation and only a weak correlation with humidity deficit. Daily values of the surface conductance necessary to estimate the actual evaporation, from the data provided by a standard climate station, were also derived.

\section{INTRODUCTION}

During the past twenty years rainfall in the West-African Sahel has been consistently less than the long-term average (Nicholson 1989). The frequency of severe droughts has increased (Sivakumar 1991), and the ability of the land to produce a reliable harvest to feed the growing populations has diminished. Traditional agriculture, which is typically a shifting millet monoculture within which areas of bushland are left fallow for years at a time, has been under pressure as the increasing population created a need for more land to be under permanent arable agriculture. Grazing, particularly by sheep and goats, and fuelwood collection prevent the re-establishment of the natural forest in these areas of fallow bushland. This combination of drought, grazing and fuelwood collection can lead to such an increased pressure on the vegetation that a process of desertification is initiated, with the vegetation becoming increasingly degraded, leaving large areas of soil exposed and vulnerable to erosion. Charney (1975) proposed a mechanism whereby the reduced solar radiation input resulting from the higher albedo of bare soil could produce an atmospheric feedback process leading to lower rainfall. General Circulation Models (GCMs) have modelled this effect (see Rowntree 1988). Less attention has been paid to modelling the effects of changes in the other surface energy fluxes which might occur as desertification proceeds. This is partly because it is only recently that the land-surface sub-models of GCMs have become sufficiently realistic to allow the incorporation of the evaporative characteristics of different vegetation types, but also because there are little, if any, data against which such models could be calibrated. This paper describes data which have been collected as part of a study to meet this need. The measurements described here were made in a fenced area of fallow bushland with a good cover of vegetation. In any investigation into the climatic effects of desertification they could be used as the limiting case of vegetation in good condition.

\section{SITE}

The measurements were made between 28 September and 10 November 1988 in an area of fallow bushland on the International Crops Research Institute for the Semi-Arid 
Tropics (ICRISAT) experimental farm at Sadoré, $45 \mathrm{~km}$ south of Niamey, Niger (Lat. $13^{\circ} 15^{\prime} \mathrm{N}$. Long. $2^{\circ} 17^{\prime} \mathrm{E}$ ). Some preliminary measurements at this site have heen described by Wallace et al. (1990). The area is flat and the site was situated so that there was a fetch of at least 300 to $500 \mathrm{~m}$ of bushland in all directions. Further details of micrometeorological aspects of the site are given by Lloyd et al. (1991). The observations were made at the start of the dry season in 1988 when the surrounding area was mainly millet stubble or grazing land. During the experiment the wind direction was changing from south-westerly, which prevails in the wet season, to north-easterly as it is in the dry season. There was thus no predominant wind direction. There was a windbreak of Neem (Azadirachta indica) trees approximately $5 \mathrm{~m}$ high on the eastern boundary of the experimental area. Measurements were made during the first six weeks of the dry season when 81 per cent of the ground coverage was a mixture of mainly annual leguminous and grass species, predominantly Cassia mimosoides. Tephrosia line'aris, Aristida mutabilis and Eragrostis tremula. The remaining ground was covered by woody shrub, (iuiera senegalensis, with an average height of $2.3 \mathrm{~m}$. There were also occasional trees, for example Balanites aegyptiaca, between 5 and $10 \mathrm{~m}$ tall and with a density of approximately 1.5 per hectare. The site was lightly grazed by the cattle, horses and donkeys, used for animal traction on the experimental farm, but not normally by sheep or goats. No animals were allowed within $200 \mathrm{~m}$ of the measurement position during the period when these measurements were being made. There was also only a small amount of fuelwood collection. The site had not been cultivated for the six years since the farm was fenced. Although it is not known how long the land had been fallow before then, an examination of the rings in the stems of the bushes indicated that the area had been fallow for a total of seven to eight years (S. J. Allen, personal communication). No measurements of leaf area were made, but in qualitative terms it was clear that as the dry season progressed, the senescence of the short vegetation resulted in a reduction of green leaf area. The soils of this area, which are sands, have been described in detail by West et al. (1984). At this site there was some 5()() $\mathrm{mm}$ of sand overlying lateritic rock.

\section{INSTRUMMINTATION}

Hourly average fluxes of water vapour, sensible heat and momentum were measured using a Mk 2 Hydra eddy-correlation device (see Shuttleworth et al. 1988). This was mounted at a height of $12.3 \mathrm{~m}$ above ground, on a mast on top of a $10 \mathrm{~m}$ high tower.

A second Hydra was mounted at the top of a variable-height, pneumatic mast. This Hydra was operated at $3 \mathrm{~m}, 6 \mathrm{~m}$ and also at $9 \mathrm{~m}$. There was also a short period when the two instruments were intercompared on the tower at $12.3 \mathrm{~m}$.

An automatic weather station was mounted at the top of the same tower as the eddy-correlation mast. This measured solar radiation, aspirated wet and dry bulb temperature, and wind speed and direction. These instruments were logged on a solidstate data logger. For the purposes of the analyses presented in this paper all the measurements were processed to provide hourly average values. Other measurements not directly relevant to this paper included reflected solar radiation, soil temperature and heat flux, and surface temperature. Net radiation was also measured, but because of doubts over the design and calibration of the instruments (Oliver and Wright 1990), the net radiation data have not been used in this analysis.

Soil moisture content was derived from 5 gravimetric samples taken along a $100 \mathrm{~m}$ transect some $25 \mathrm{~m}$ to the south of the observation tower. The samples were taken to $a$ depth of $500 \mathrm{~mm}$. Measurements were made once after the only substantial rainstorm during the observation period, and otherwise at weekly intervals. The transect was movec 


\section{(b) Evaporation}

Evaporation was recorded on 28 September 1988 and then continuously from 2 October to 10 November 1988 inclusive. The daily totals of evaporation for this period are shown in Fig. 2. For days with missing data the daily totals have been derived by linear interpolation between hours with data. These periods, of up to three hours. occurred when the instrument was being serviced, normally only once a week. As a comparative index the Penman potential evaporation calculated from the agrometeorological station data is also shown in Fig. 2. The method of calculation follows that given by Jensen (1973), with net radiation being calculated from solar radiation

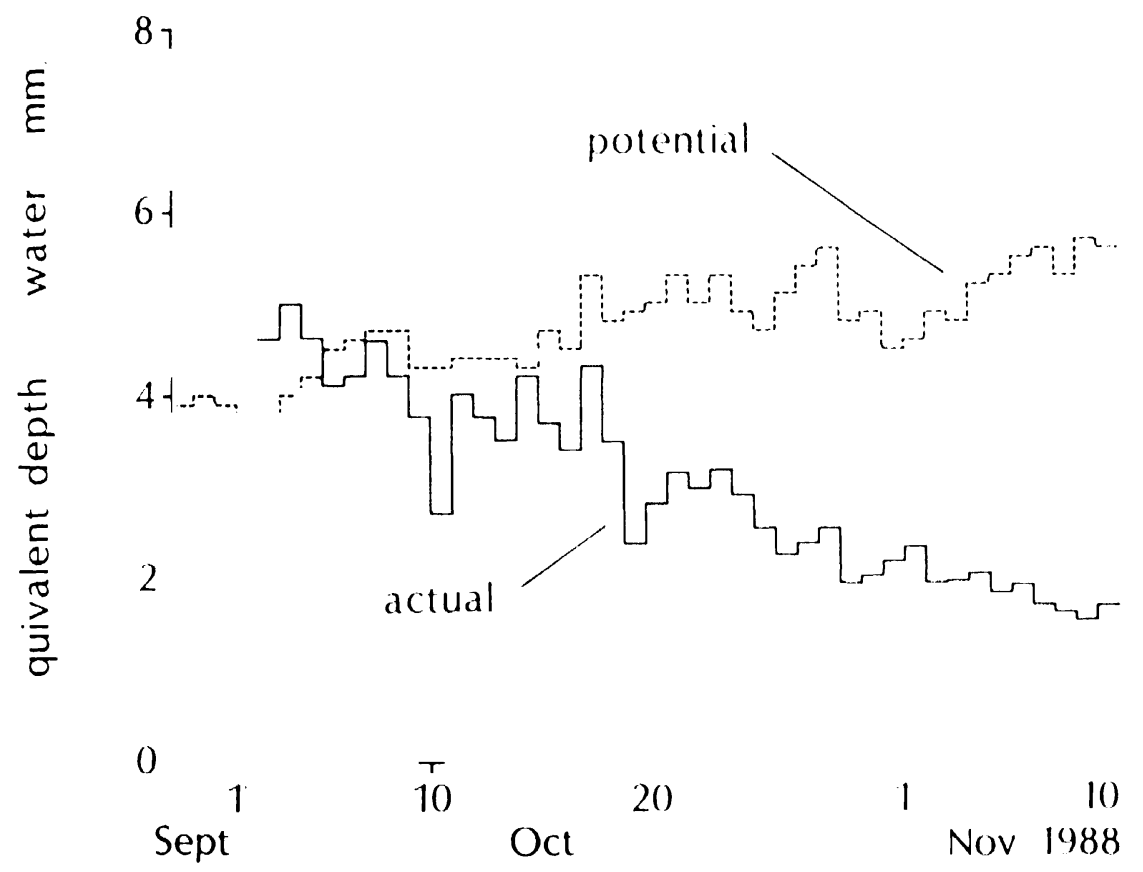

Figure 2. Variation in daily evaporation, as measured by the eddy-correlation instrumentation. compared with the Penman potential evaporation during the measurement period.

using an empirical relationship derived from previous measurements over a millet crop at this site. Full details are given by van Donk et al. (1989). Midday solar radiation was typically $900 \mathrm{~W} \mathrm{~m}^{-2}$; minimum temperatures were typically $23^{\circ} \mathrm{C}^{\circ}$ and maxima $36^{\circ} \mathrm{C}^{\circ} \mathrm{C}$. During the course of the measurement period the specific humidity fell from some $15 \mathrm{gkg}^{1}$ at the start, to more typically $5 \mathrm{gkg}{ }^{1}$ at the end.

Rainfall during the measurement period is shown in Fig. 3: the only substantial rainfall occurred on 28 September. The decline in the soil moisture content of the top $500 \mathrm{~mm}$ of soil. expressed as percentage of the maximum value observed during the study, is also shown in Fig. 3.

Figures 2 and 3 show that the evaporation remained close to potential for the first ten days following the end of the wet season, but then declined. By the end of the measurement period, i.e. after six weeks without rain, the evaporation was less than 30) per cent of potential. While this was partly a result of the increase in potential evaporation in response to the greater humidity deficits encountered as the dry season progressed, there was also a decline in evaporation in absolute terms from approximately 4.5 to $1.5 \mathrm{~mm}$ per day. There is a steady decline in the evaporative fraction, or the percentage of the available energy used for evaporation. This is shown in Fig. 4, calculated from the 
$1 \mathrm{~m}$ to the south for each new measurement to avoid any areas where the vegetation had been damaged by the previous sampling.

The climatological data were taken at the standard agrometeorological station situated about $1 \mathrm{~km}$ from the experimental site. Readings of temperature, humidity, windspeed and solar radiation were made at $(17(0)$ and $1.3(0)$ (iNT: daily maximum and minimum temperature were also recorded.

\section{RESUTS}

\section{(a) Filch}

The principal eddy-correlation instrument was mounted at a height of $12.3 \mathrm{~m}$, so as to ensure that it was above the height of the trees. accepting that this might give an unacceptably short fetch. For this site Lloyd et al. (1991) derived a value for the zeroplane displacement of $0.93 \mathrm{~m}$ and for the roughness length of $0.17 \mathrm{~m}$. Using these values, Gash's (1986) formula (as corrected by Schuepp et al. 1990) predicts that for neutral conditions and an infinite fetch, 48 per cent of the measured flux may be from beyond $400 \mathrm{~m}$. If there were a 30 per cent step-change in flux beyond $4(1) \mathrm{m}$. Gash s $(1986)$ formula would predict a measurement error of 14 per cent. Apart from the days immediately after the rain it might be expected that the bare soil upwind of the fallow area would be evaporating less and therefore lead to an under-measurement in evaporation and an over-measurement in heat flux. However, when the fluxes of evaporation and sensible heat from the Hydra at the fixed height are compared with those from the variable height mast in Fig. 1, the reverse appears to be true. The fect for the highest instrument is thus probably adequate: the observed differences may be the result of instrumental error and the fact that the instruments at different heights are sampling different areas of vegetation. The enhanced diffusion which occurs under unstable conditions also acts to reduce the fetch requirement. Leclere and Thurtell (1990) have illustrated the effect of stability on fetch: in the example that they considered 48 per cent of the flux came from within $420 \mathrm{~m}$ under neutral conditions, but this increased to 6.5 per cent under unstable conditions (with the Monin-Obukhov length equal $t(0-10 \mathrm{~m}$ ). Using the windspeed and friction velocity data collected at the same time as these data, Lloyd et al. (1991) also concluded that from an aerodynamic point of view the fetch was adequate.

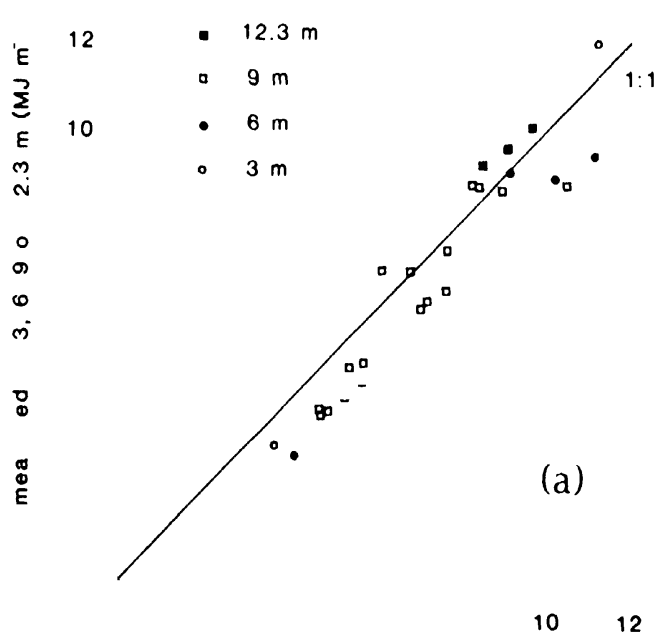

Flux measured at $12.3 \mathrm{~m}\left(\mathrm{MJ} \mathrm{m}^{-2}\right)$

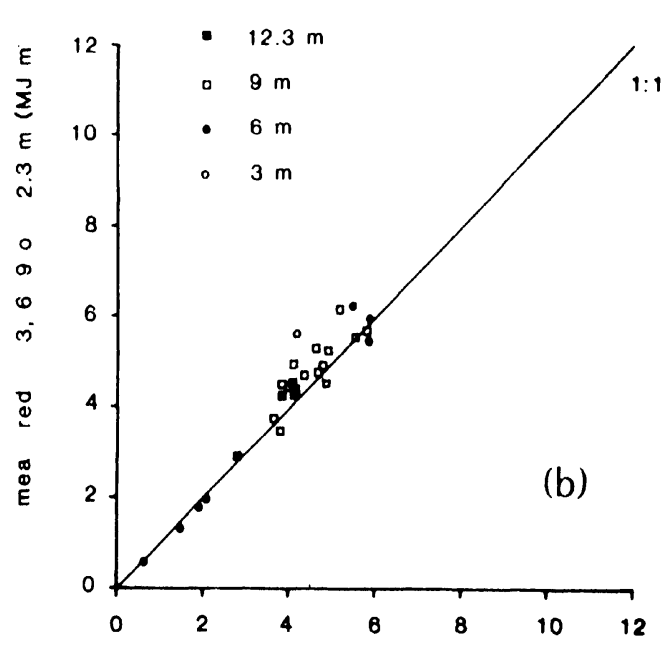

Flux measured at $12.3 \mathrm{~m}^{(M J} \mathrm{m}^{-7}$ )

Figure 1. The daily totals of: (a) evaporation. and (b) sensible heat flux, measured by the instrument at $12.3 \mathrm{~m}$, against that measured by a similar instrument at various different heights. 


$$
100
$$

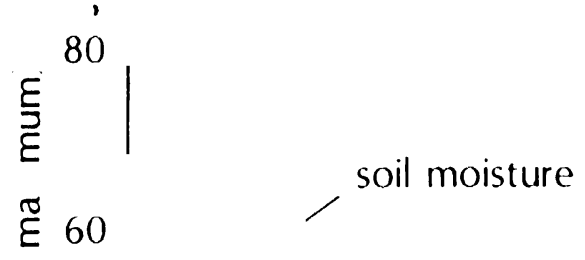

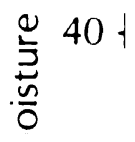

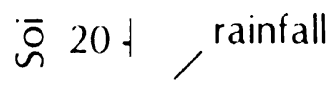

Figure 3. Variation in the soil moisture in the $t(0) .500) \mathrm{mm}$ soil depth, as a percentage of the maximum observed during the period of observations. dedeced from gravimetric sampling. The rainfall is also shown.

$$
1.0 \neg
$$

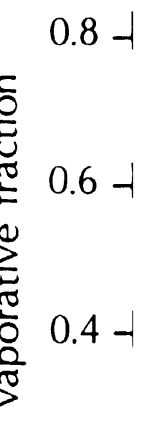

$$
0.2-1
$$

$\begin{array}{llr}20 & 10 \\ \text { Oct } & & 10\end{array}$

Figure 4. The variation in the evaporation fraction, calculated for each day as the average ratio of evaporation to the sum of evaporation and sensible heat flux, from the hourly data used in the surface conductance analysis. 
data used later in the surface-conductance analysis, as the ratio of evaporation to the sum of evaporation and sensible heat flux. This decline in evaporation is also illustrated in Fig. 5 which shows the daily trend in evaporation and sensible heat flux for two example days, one near the start of the measurement period and one near the end. The soil moisture in the top $500 \mathrm{~mm}$ declined for the first two weeks of the dry season but then remained virtually constant, implying that during the last four wecks of measurements the evaporated water must have been extracted from below $5(x) \mathrm{mm}$. Assuming an evaporation rate of $5 \mathrm{~mm}$ per day for the three days of missing data starting on 24) September. over the whole period of observations $135 \mathrm{~mm}$ of water was observed to be evaporated, of which $78 \mathrm{~mm}$ came from the soil below $500 \mathrm{~mm}$ during the last four wecks of measurements.

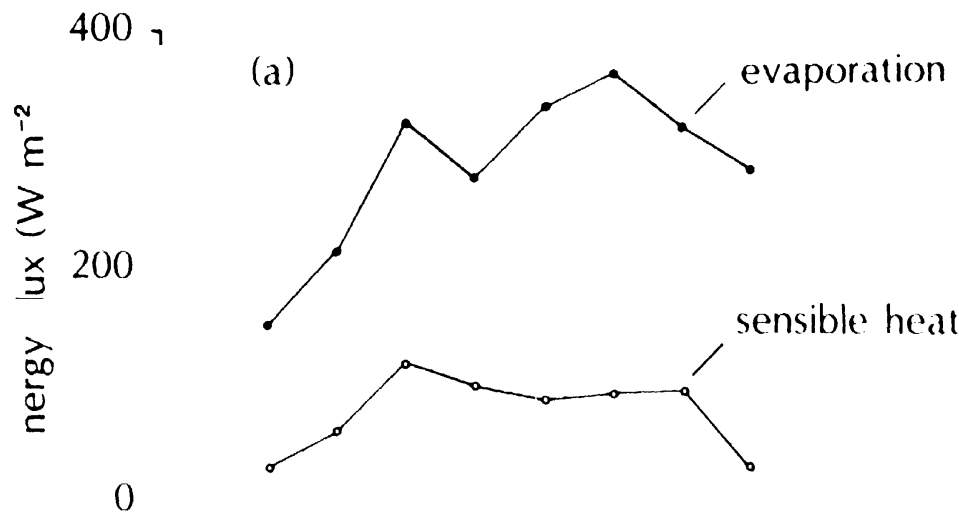

4007

(b)

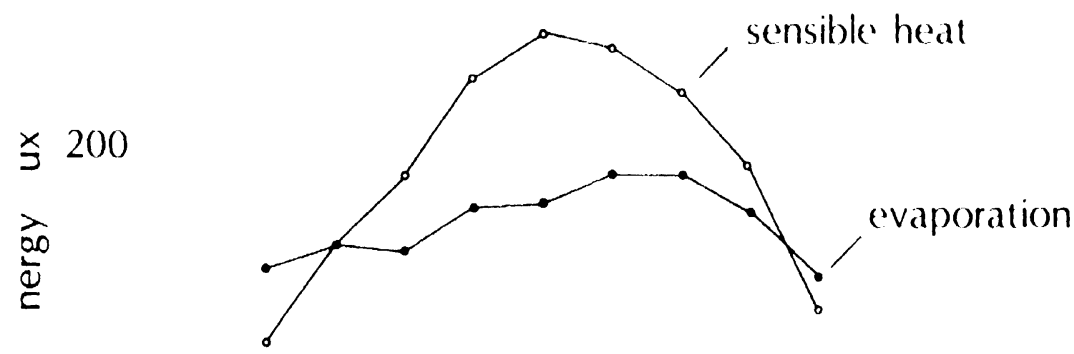

0

Iime (GMT)

Figure 5. Diurnal variations in evaporation and sensible heat flux for: (a) 9 October l98x, near the start of the observation period; and (b) 6 November 1988 , near the end of the period. There was no rainfall in between these two dates.

\section{(c) Surface conductance}

The surface conductance, $g_{s}$, has been derived using the inverted form of the Penman-Monteith equation:

$$
1 / g_{s}=\left\{\left(\lambda s^{\prime} / c_{p}\right) \beta-1\right\} / g_{\mathrm{a}}+\rho D^{\prime} / E
$$

where $s^{\prime}$ is the rate of change of saturated specific humidity with temperature, $\rho$ is the density of air, $\lambda$ is the latent heat of vaporization of water, $c_{p}$ is the specific heat of air 
at constant pressure, $D^{\prime}$ is specific humidity deficit at the reference height. $\beta$ is the Bowen ratio and $E$ is the evaporation rate. The aerodynamic conductance for vapour flux, $g_{i}$. was derived from the aerodynamic conductance to momentum flux obtained from the eddy-correlation measurement of the friction velocity. ${ }_{*}$. and the windspeed at the reference height, $u$. The effects of stability and differences in the sources and sinks of water vapour and momentum are taken account of, as described by Verma (1989), such that

$$
1 / g_{\mathrm{a}}=u^{\prime} u_{*}^{2}+\left\{\ln \left(z_{0} / z_{h}\right)+\psi^{\prime} m-\psi_{h}^{\prime}\right\} / k u_{*}
$$

where $k$ is von Karman's constant, and $z_{11}$ and $z_{\text {h }}$ are the roughness lengths for momentum and heat respectively. From measurements over a somewhat similar savannah-type surface Garratt $(1978)$ found $\ln \left(z_{0} / z_{h}\right)$ to be 2.5 , and that value has been used here. $\psi_{h}$ and $\psi^{\prime} \mathrm{m}$ are the integral diabatic correction factors for heat and momentum transfer; the formulae given by Paulson (1970) have been used in this analysis.

The analysis was restricted to hours when the net radiation was positive. Hours with positive momentum flux (negative $u_{*}^{2}$ ), which can oceur at low windspeeds when the cup anemometer is within its stalling region, were also omitted. Between 3 and 5 ()etober the fast-response thermometer did not work, there were no heat flux measurements, and therefore the surface conductance could not be calculated. This gave a total of 260 hours available for analysis.

Figure 6 shows the individual surface-conductance data-points for each day throughout the observation period. The few points obtained on the days immediately following the rainfall at the end of September, i.e. 1 to 3 (October, show conductances in the range 11 to $22 \mathrm{mms}$ ', but by 6 October the conductances had fallen rapidly to between 4 and $7 \mathrm{mms}$ '. Figure 7 shows the trends in surface conductance for the two days at the start and end of the measurement period shown in Fig. 4. On both days, after declining for the first few hours, the conductance changes relatively little for the remainder of the day. A similar trend in surface conductance was observed by Kim and Verma (199()) for

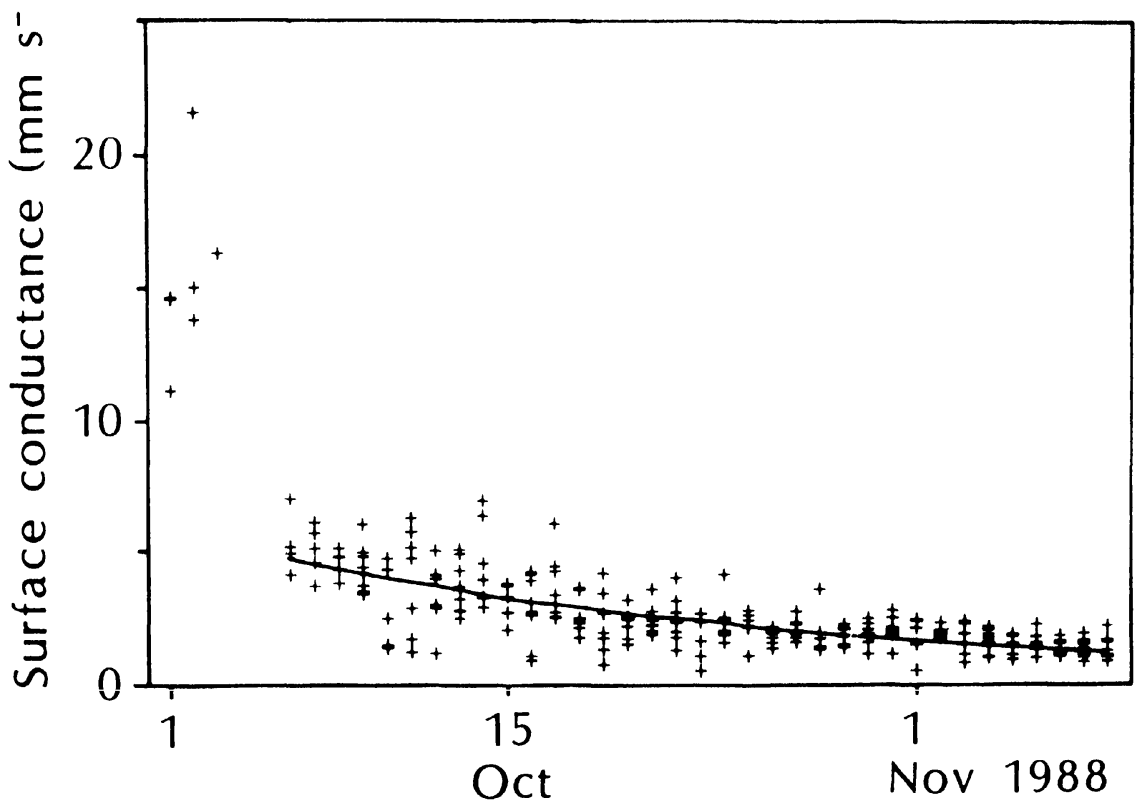

Figure 6. The hourly surface conductance for each day plotted against date. The curve is the result of fitting Eq. (4) to the data from 6 October 1988 onwards. 


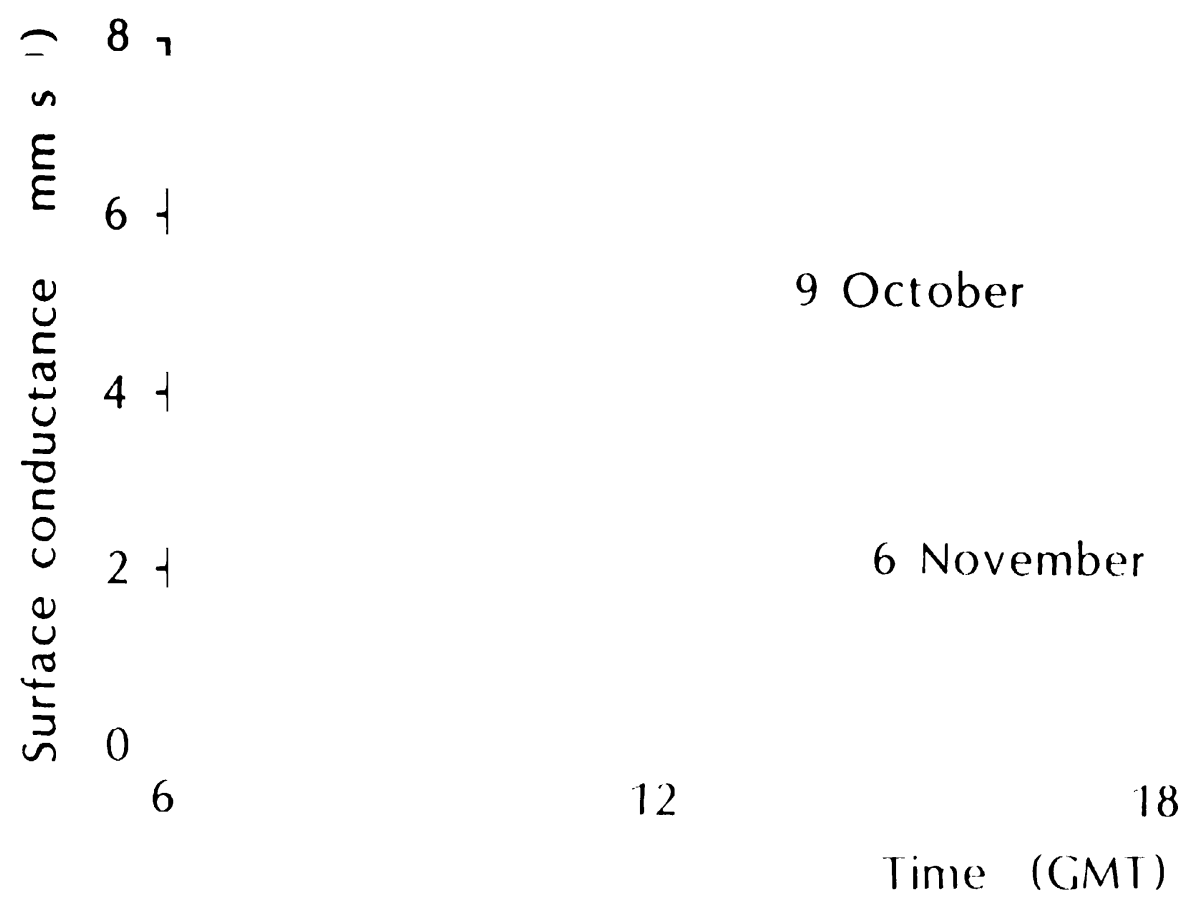

Figure 7. The surface conductance for the same days as shown in fig. 4. logether with the curves showing the result of applying Eq. (4) with the parameters as given in Table 1 derived from the whole data-set.

drought-stressed prairie grass. The decline in surface conductance as the dry season progresses is the dominant feature of the data apparent in Figs. (5) and (6); hy the end of the measurement period conductances had fallen from values of about $4 \mathrm{mms} \mathrm{s}^{1}$ to between 1 and $2 \mathrm{mms}^{-1}$.

The Penman-Monteith equation assumes a one-dimensional transfer of water vapour from a hypothetical single source. Savannah bushland is a natural vegetation with complex three-dimensional structure. It has at least two distinct major vegetation classes- the bushes, and the shorter grasses and legumes. Evaporation from the soil surface adds extra variation. The high conductances observed on the days following rainfall are clearly the result of transpiration being augmented by direct evaporation from the soil surface. The surface conductance is then a combination of canopy conductance, which represents the stomatal control on transpiration, and a soil surface conductance, which represents the physical restriction on evaporation from the soil. A single-level description is probably not the most appropriate model under these circumstances and no attempt has been made to represent these data with a descriptive relationship. However after 6 ()etober the evaporation from the soil can be assumed to be negligible and the change in surface conductance should represent the response of the system to the increasing soil-moisture deficit and the reducing green leaf area. As it is not possible to separate these effects, modelling the decline in conductance during that part of the observation period has been restricted to reproducing the combined effect as a simple empirical description in terms of elapsed time. Although such simple descriptions lack the generality and realism of more complex treatments they will be useful for calibrating those GCM land surface submodels, such as that of Warrilow and Buckley (1989), which require only a single value of the unstressed surface conductance for a given land-surface type. The simplest approach is to fit a curve through all the data with the form:

$$
g_{\mathrm{s}}=a_{1} \mathrm{e}^{h(n-8)}
$$


TABLE 1

\begin{tabular}{cccccc}
\hline Equation & $a_{1}$ & $a_{2}$ & $a_{3}$ & $b$ & $r:$ \\
\hline$(3)$ & 4.75 & & & -0.041 & 0.57 \\
& $(0.15)$ & & & $(0.012)$ & \\
$(4)$. & 4.94 & -0.30 & -0.023 & $-0 .(1) 41$ & 0.65 \\
& $(0.16)$ & $(0.05)$ & $(0.016)$ & $(0.0) 2)$ & \\
$(8)$ & 4.57 & & & -0.045 & 0.85 \\
& $(0.21)$ & & & $(0.0(0) 4)$ & \\
\hline
\end{tabular}

The coefficients derived for Eqs. (3). (4) and (8), together with the correlation coefficients. The standard errors are given in brackets.

where $n$ is the number of days since the last substantial rain and the description starts on day 8,6 October 1988. For this curve the correlation coefficient, $r^{2} .=0.57$, the parameters are given in Table 1 and the curve is plotted in Fig. 6. The fit can be improved by also taking account of the variation within the day, assuming that all those environmental controls on surface conductance which are driven by the diurnal cycle of solar radiation result in a reproducible variation each day. An equation of the form

$$
g_{s}=\left\{a_{1}+a_{2}(t-12)+a_{3}(t-12)^{2}\right\} \mathrm{e}^{b(n-x)}
$$

gives $r^{2}=0.65$. The parameters tor this equation are again given in Table 1. The result of evaluating Eq. (4) is also shown in Fig. 7, for the two example days at the start and end of the measurement period.

From a plant physiological point of view a more realistic description of surface conductance should also take account of its variation in response to environmental conditions. As well as green leaf area index and soil moisture, solar radiation and atmospheric humidity deficit are normally seen to be correlated with plants' stomatal control. However in the present case, with the exception of the long-term decline in surface conductance with elapsed time (and thus with green leaf area and soil moisture), the range of variation is narrow. As can be seen from Fig. 7 there is little change in surface conductance over the day. At this latitude the solar radiation rises and falls rapidly at the start and end of each day, and there are almost no data for solar radiation less than $300 \mathrm{~W} \mathrm{~m}^{-2}$, the range normally observed for a response to radiation. As a zonsequence there is no obvious response of the surface conductance to solar radiation, and the stomata appear to be light-saturated for all the data collected. Dividing the data into three periods to reduce the influence of the long-term decline in surface conductance, it is possible to derive a relationship between surface conductance and humidity deficit, but the correlation is poor. For example a regression between surface conductance, in $\mathrm{mm} \mathrm{s}^{-1}$, and specific humidity deficit, in $\mathrm{g} \mathrm{kg}^{1}$, for the middle period between 16 and 25 October inclusive, gave the relationship:

$$
g_{s}=3.86( \pm 1.11)-0.054( \pm 0.019) D^{\prime}
$$

with $r^{2}=0.10$.

\section{(d) Daily evaporation: the Thom and Oliver approach}

For many hydrological and agricultural applications sufficiently frequent meteorological data will not be available to allow the Penman-Monteith equation to be used to estimate hourly evaporation. For most situations the only data available will be those from a standard climate station, such as the agrometeorological station used to derive the potential evaporation estimates shown in Fig. 2. Although such data are normally only used to derive potential evaporation, given an appropriate value of the surface 


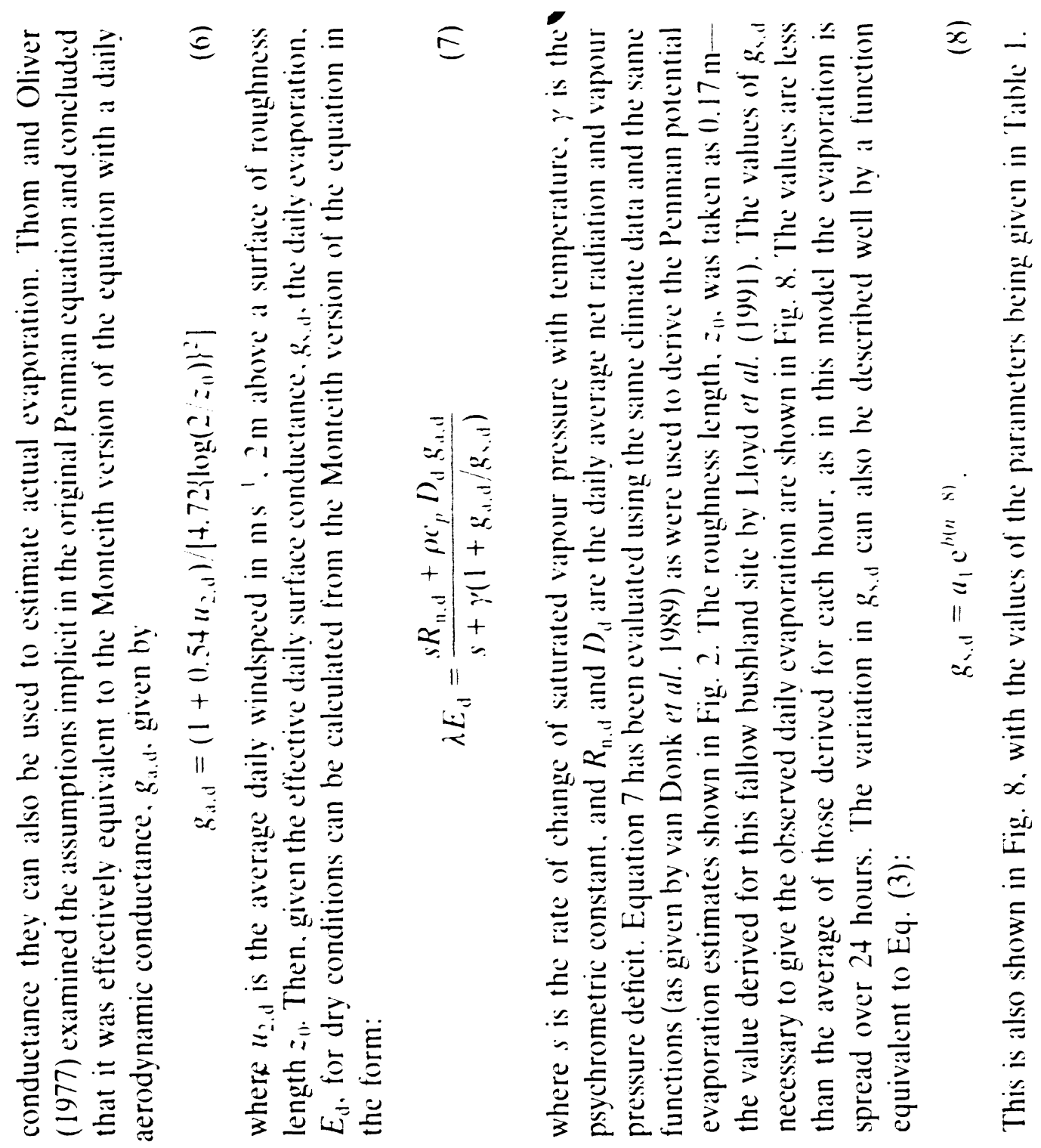

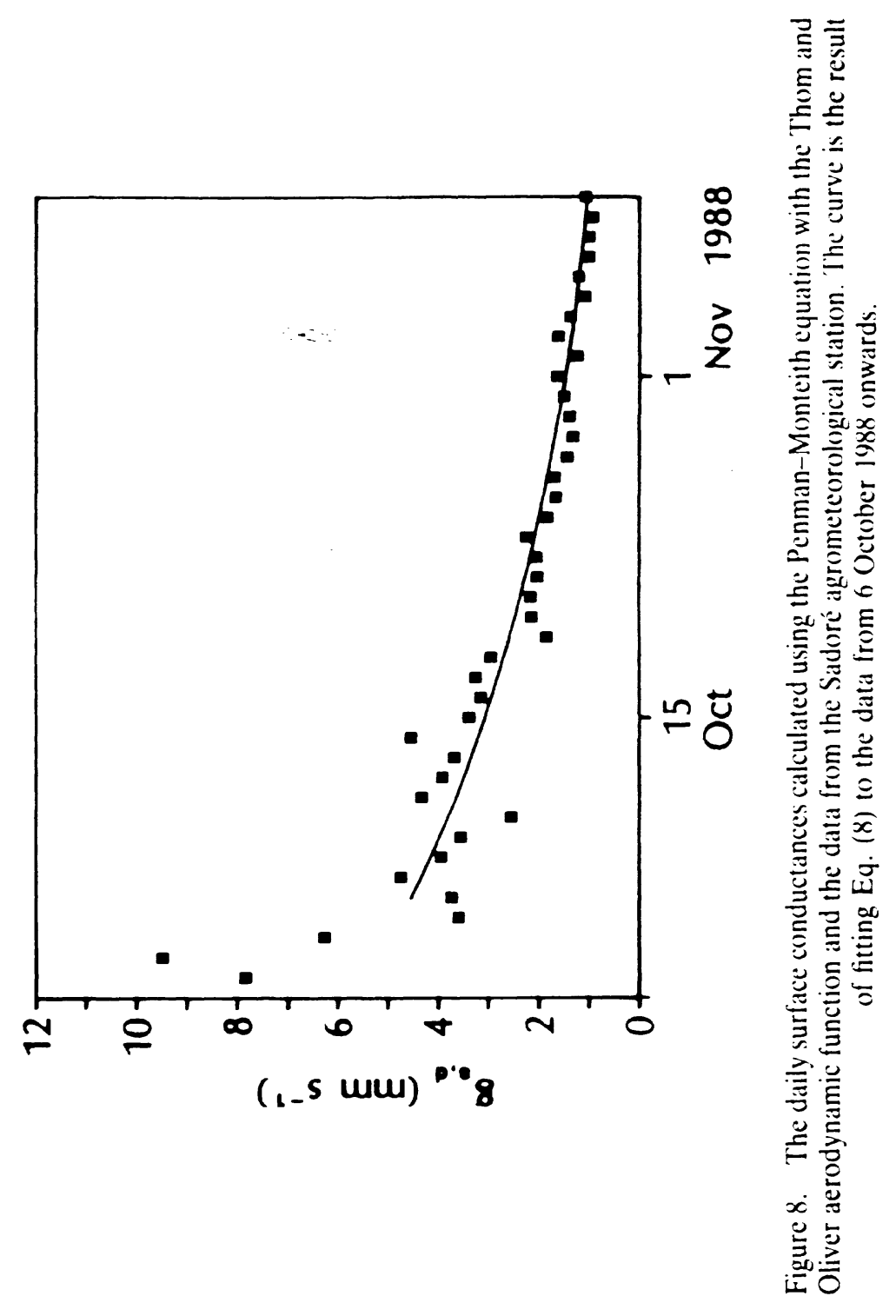




\section{CONCLUIDING REMARKS}

The results presented here are intended to provide some preliminary data on the rates of evaporation and the conseguent surface conductances which might be expected from this type of Sahelian savannah vegetation at the start of the dry seasson. The data demonstrate that the evaporation remains close to potential for ten days after the last rainfall. After that, when some $50 \mathrm{~mm}$ of water have been evalporated, the rate of evaporation falls, but even after tive wecks. when some $1.35 \mathrm{~mm}$ have heen evaporated. there is still appreciable evaporation with rates of 1 to $2 \mathrm{~mm}$ per day.

The high values of the surface conductance measured in the days immediately after the last rain emphasize that the surface conductances are bulk values which represent the restriction to evaporation from the surface as a whole. Shuttleworth and ciurney (1990) have shown that for canopies with low leaf areas, surface conductances such as these will be a poor representation of the physiological behaviour of the canopy. To understand the controls on evaporation it will be necessary to model the contributions of the individual components, separating the fluxes from the vegetation and the soil. A more comprehensive data-set, including data from the wet season, will be necessary to achieve this.

In terms of modelling the atmospheric circulation. these data represent only one vegetation type in one part of the Sahel. There are also large areas of sparse forest (tiger bush), as well as substantial areas of millet. The evaporation from these vegetation types is to be investigated in subsequent phases of this project. In addition the strong rainfall gradient across the Sahel creates a corresponding gradient in the vegetation. This creates a problem in representing the area at the $100 \mathrm{~km}$ scale required for climate modelling. This problem will be addressed by HAPEX-Sahel, an international experiment planned for 1992, when simultaneous measurements will be made at multiple sites over a (; $\mathrm{M}$ grid-square-sized area in the same region as that where the present data have been collected.

\section{A(KNOWILI)( BMI:NTS}

The results presented here were obtained as part of an extensive programme of research into the energy balance of Sahelian vegetation supported by the ()verseas Development Administration and the Natural Environment Research (ouncil. AJI) holds a CEGB Senior Rescarch Fellowship supported by the Joint Environmental Programme of National Power and PowerGen. We also thank our colleagues S. Abdoulsalam, D. D. McNeil, M. R. Stroud, M. Turner and I. R. Wright for their help in the preparation of the instrumentation and the collection of the data.

\section{RIIFTINCIS}

Charncy, J. G.

Garratt, J. R

Gash, J. H. C

Jensen, M. E.

Kim, J. and Verma, S. B.

Leclerc, M. Y. and Thurtell, G. W.
1986

1973

1975

1978

1990

Dynamics of deserts and drought in the Sahel. (). J. $R$. Meleorol. Soc., 101, 193-2(1)

Transfer characteristics for a heterogencous surface of large aerodynamic roughness. (). J. R. Meleorol. Soc., 104, $491-5(1) 2$

A note on estimating the effect of a limited fetch on micrometeorological evaporation measurements. Boundarylaver Meteorol. 35, 409-413

Consumptive Use of Water and Irrigation Water Requirements. American Socicty of Civil Engineers

Components of the energy balance in a temperate grassland ecosystem. Boundary-Layer Meterorol., 51, 4()1-417

Footprint prediction of scalar fluxes using a Markovian analysis. Boundary-Laver Meteorol. , 52, 247-258 
Llovd. C. R., Gash. J. H. C. and Sivakumar. M. V. K.

Nicholson, S. E.

Oliver, H. R. and Wright. I. R.

Paulson, C. A.

Rowntree, P. R.

Schuepp, P. H., Leclerc, M. V..

199() MacPherson, J. I. and Desjardins. R. L.

Shuttleworth, W. J., Gash. J. H. C., 1988 Lloyd, C. R.. McNeil, D. D., Moore, C. J. and Wallace. J. S.

Shuttleworth. W. J. and Gurney, R. J.

Sivakumar, M. V. K.

Thom, A. S. and Oliver, H. R.

van Donk. S. J., Sivakumar. M. V. K. 1989 and Kanemasu, E. T.

Verma, S. B.

1989

Wallace, J. S., Gash, J. H. C. and Sivakumar, M. V. K.

Warrilow, I). A. and Buckley, E.

1989

West, L. T., Wilding, L. P., Landeck, J. K. and Calhoun. F. G.
1991 Derivation of the acrodynamic parameters for a Sahelian sav. annah site using the eddy correlation technique. Boundary-Layer Meteorol. (in press).

1989 Long-term changes in African rainfall. Weather. 44, 46-64

199() Correction of errors associated with measurement of net allwave radiation with double domed radiometers. Boundary-layer Meteorol. . 53, 4()1-407

1970) The mathematical representation of wind speed and temperature profiles in the unstable atmospheric surface laver. J. Appl. Me'teorol., 9, 857-861

Review of general circulation models as a basis for predicting the effects of vegetation change on climate. Pp. 162-196 in Forests, (limate and Hidrologly: Regional Impacts. Eds. E. R. C. Evans and F. B. Thompson, United Nations University

Footprint prediction of scalar fluxes from analytical solutions of the diffusion equation. Boundary-Laver Mefeorol. 50. $355-37.3$

An integrated micrometeorological system for evaporation measurement. Agric. For. Meteorol. 43, 295-317

The theoretical relationship between foliage temperature and canopy resistance in sparse crops. ( . J. R. Meteorol. Soc., 116, 497-52()

Climatic change and implications to agriculture in Niger. (lim. ('hange' (in press)

On Penman's equation for estimating regional evaporation. Q. J. R. Meteorol. Soc., 103, 345-3.57

Estimation of Penman potential evaporation for the West African Sahel with an IBM P(". Report 89-128D). Kansas Agricultural Experiment Station, Kansas State University

Acrodynamic resistances to transfers of heat. mass and momentum. In Estimation of areal enaporation. Fds. T. A. Black, D. L. Spittlehouse, M. D. Novak and D. 'T. Price. IAHS Publication 177. IAIIS Press, Wallingford

Preliminary measurements of net radiation and evaporation over bare soil and fallow bushland in the Sahel. Int. J. ( lim., 10, 2(1)-210

of a climate model Annales (jeophwsicae, 7, 439-450)

1984 'Soil survey of the ICRISAT Sahelian (enter, Niger, West Africa. Soil and ('rop Sciences Department/Tropsoils, Texas $A$ and $M$ University 